\title{
DURABILIDAD NATURAL Y DESCRIPCIÓN ANATÓMICA DE LA MADERA DE LA ESPECIE Caryodaphnopsis cogolloi van der Werff
}

\author{
Natural durability and anatomy of wood of Caryodaphnopsis cogolloi van der Werff
}

Palabras clave: agar block, Gloeophyllum trabeum, macroscopía, patrones de degradación, soil block, Trametes versicolor

Keywords: Agar block, Gloeophyllum trabeum, macroscopy, decay patterns, soil block, Trametes versicolor.

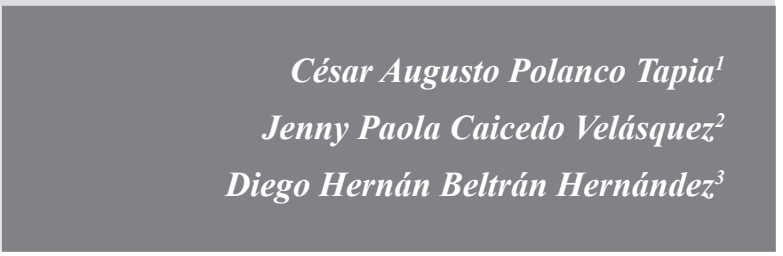

y de $5.9 \%$ para los dos hongos en agar block. Los patrones de degradación de los hongos en la madera mostraron que $T$. versicolor erosionó la pared celular y generó el ensanchamiento de las punteaduras en algunas células, mientras que G. trabeum produjo la disminución del espesor de las paredes celulares en pocas células. Este estudio se reporta como el primero en durabilidad natural para la especie $C$. cogolloi.

\begin{abstract}
The wood anatomy of Caryodaphnopsis cogolloi van der Werff was studied using xilological characteristics identified in transverse and longitudinal wood cuts (tangential and radial views). Wood natural durability was established in an accelerated laboratory trial, using two methods: a soil block method established by the Colombian Technical Standard NTC 1127 (NTC for its acronym in Spanish), and an Agar block method ruled by the standard norm EN 350-1: 1994 in which the decay fungi used were Trametes versicolor and Gloeophyllum trabeum. The durability was assessed by weight loss and analysis of the fungal decay characteristics over a four month
\end{abstract}

1 Universidad Distrital Francisco José de Caldas. cpolanco@udistrital.edu.co Autor para correspondencia.

2 Universidad Distrital Francisco José de Caldas. jepao13@hotmail.com

3 Universidad Distrital Francisco José de Caldas. diegodistrital@gmail.com 
incubation period on the wood samples where each month the colonization mechanism, development and fungal growth characteristics were observed, along with the effects on the cell wall. Caryodaphnopsis cogolloi wood is significantly resistant to fungal white and brown rotting showing a mean weight loss of $5.1 \%$ and $6.1 \%$ respectively in the soil block method, while in the agar block method the weight loss was $5.9 \%$ for both fungi. Decay patterns in the samples demonstrated that $T$. versicolor eroded cell walls and produced enlargement in the cell wall holes in some cells, while G. trabeum produced a reduction in cell wall thickness in a few cells.

\section{INTRODUCCIÓN}

La especie Caryodaphnopsis cogolloi van der Werff (Yumbé) se caracteriza por alcanzar alturas de $30 \mathrm{~m}$ y diámetros aproximados de $50 \mathrm{~cm}$. Las hojas son opuestas, decusadas, con 15 a $20 \mathrm{~cm}$ de largo y 5 a $8 \mathrm{~cm}$ de ancho. Su ápice es acuminado y la base aguda. Tanto el haz como el envés son glabros. El haz es verde y el envés glauco. La longitud de los peciolos oscila entre 1.5 y $2.0 \mathrm{~cm}$, y presenta pubescencia diminuta ferrugínea. Las inflorescencias son axilares con longitudes cercanas a los $8 \mathrm{~cm}$ de longitud, las flores amarillas con pedicelos entre 2 y $3 \mathrm{~mm}$ de largo y 6 tépalos desiguales, 9 estambres glabros de $2 \mathrm{~mm}$ de longitud, con 4 locelos cada uno; de estos los 3 más internos con 2 glándulas globosas y pequeñas en la base. El ovario es globoso con un diámetro promedio de $0.5 \mathrm{~mm}$, con presencia de filamentos cafés. El fruto es ovoide (van der Werff, 1988).

Su distribución está restringida a una localidad ubicada en el cañón del río Claro, Reserva Natural El Refugio. El uso principal que se le da a la especie, aun estando en estado de amenaza crítico, es maderable, principalmente para construcción local de estacones para cerca (Cárdenas \& Salinas, 2007), dada su alta resistencia a la pudrición, excelente trabajabilidad y estética agradable, lo que ha generado una sobreexplotación de la especie, poniendo en riesgo su permanencia en el tiempo.

El alto grado de resistencia de la madera de esta especie al biodeterioro está determinado por sus características intrínsecas, tales como composición química de la pared celular, presencia de otros compuestos químicos en las cavidades celulares, permeabilidad, contenido de humedad y temperatura, y por las condiciones finales de uso (Findlay, 1985; Guevara \& Lluncor, 1993). Dentro de estos procesos y en ambientes húmedos, la pudrición está considerada como una de las mayores causas de deterioro microbiológico que afectan su durabilidad y ocasionan fallas estructurales sobre elementos en servicio, siendo causada por hongos que utilizan la madera y sus componentes como fuente de alimentación (Mora \& Encinas, 2001).

Las maderas con una capacidad natural de repeler el ataque de hongos e insectos y resistir el desgaste mecánico, la acción de los agentes atmosféricos y el fuego tienen alta durabilidad natural (Scheffer \& Cowling, 1966; Gonzalez, 1970; Zabel \& Morrell, 1992; Guevara \& Lluncor, 1993; Ramírez et al., 2005; Holmquist et al., 2006; Holmquist et al., 2007), la cual es dada por el conjunto de sus propiedades, específicas para cada especie, que le confieren una determinada resistencia cuando son utilizadas sin ningún tratamiento preservante (Bobadilla et al., 2005; Córdoba, 2009).

Dentro de estos agentes que degradan la madera el mayor daño lo ocasionan los hongos xilófagos (JUNAC, 1988; Nunes \& de Sousa, 1995), responsables de grandes pérdidas económicas (Bobadilla et al., 2005; Holmquist et al., 2007), por las afectaciones generadas en la madera, siendo estas principalmente pudriciones, manchas y mohos (Martínez, 1952).

Los hongos xilófagos degradan moléculas complejas como la celulosa, las hemicelulosas, las pectinas, el almidón y la lignina (Akhtar et al., 1998; Breen \& Singleton, 1999). Pueden clasificarse en varios grupos de acuerdo a la forma de vida y al tipo de deterioro que ocasionan. La mayoría de los hongos pudridores pertenecen a la clase Basidiomicetes; dentro de estos, los hongos lignícolas son los más importantes, ya que son capaces de desintegrar las paredes de la célula, desintegrando la lignina por oxidación (pudrición blanca) y la celulosa por hidrólisis (pudrición marrón) (Eaton \& Hale, 1993), 
cambiando la composición química y las propiedades físicas, mecánicas y anatómicas de la madera. Tal desorganización de la materia da lugar al estado llamado pudrición (Intini \& Tello, 2003). Por ello, el término durabilidad suele asociarse con la resistencia a la degradación fúngica (Zabel \& Morrell, 1992; Mohali \& Castro, 2005; Holmquist et al., 2006).

Respecto a la madera de la especie objeto de estudio, los pobladores locales del Magdalena Medio aprecian sus características de fácil trabajabilidad, alta durabilidad y estética agradable, al ser utilizada en exteriores, principalmente como estacones y macanas sin ningún tipo de tratamiento. Pese a las grandes cualidades que posee la madera de $C$. cogolloi, aún no se encuentra ningún reporte de sus características anatómicas e índices de durabilidad natural, por lo que en el presente estudio se reporta por primera vez la descripción xilológica de la especie Caryodaphnopsis cogolloi van der Werff y se determina su índice de durabilidad natural, a través de los métodos agar block y soil block, frente al ataque dos tipos de hongos: Trametes versicolor y Gloeophyllum trabeum.

\section{MATERIALES Y METODOS}

\section{AREA DE ESTUDIO}

La madera fue extraída de los bosques húmedos tropicales del Magdalena Medio colombiano, ubicados al suroccidente del departamento de Santander, municipio de Landázuri, corregimiento La India. Esta zona posee tierras en altitudes que van desde los 200 a los 500 m.s.n.m., los suelos son desarrollados, moderadamente profundos a superficiales, con texturas medias, excesivamente drenados, fertilidad baja a muy baja, toxicidad por alto contenido de aluminio, pobres en bases y alto contenido de carbono orgánico, características que los hacen aptos para bosques; la zona presenta un comportamiento climático bimodal, sobre el piso térmico cálido, con temperatura anual promedio que oscila entre 27 y $29^{\circ} \mathrm{C}$, y precipitación promedio anual entre 2000 y $2500 \mathrm{~mm}$ (Reforestadora Bosques del Futuro S.A., 1996). La ganadería y la agricultura son las principales actividades económicas que desarrollan la población, pero también se ha dado la sobrexplotación de maderas y la siembra de cultivos ilícitos que han causado la deforestación masiva y la destrucción de bosques primarios (Equipo Subregión de Vélez, 1998).

La especie ha sido registrada en inventarios forestales como el realizado por la Reforestadora Bosques del Futuro S.A. en 1996, donde se encontraron 385 árboles de diferentes especies por hectárea, de los cuales solo 0.57 árboles eran de Caryodaphnopsis cogolloi van der Werff.

Para 10.5 hectáreas inventariadas, el volumen de esta madera llegó a $9.18 \mathrm{~m}^{3}$ equivalente al $2.85 \%$ del volumen total registrado $\left(118.5 \mathrm{~m}^{3} / \mathrm{ha}\right)$ para todas las especies inventariadas con DAP mayor a $10 \mathrm{~cm}$.

\section{OBTENCIÓN DE MUESTRAS}

Para la colección del material se hizo una solicitud formal a la Asociación de aserradores del corregimiento La India, quienes por medio de personal experto, suministraron duramen de la especie según su denominación local (Yumbe). Los aserradores llevaron el material hasta las playas de comercialización, donde se realizó la colecta por parte de los autores. In situ, se practicó la verificación de la especie, dadas las características macroscópicas del leño. Se tomaron en total dos bloques procedentes de igual número de árboles, los cuales se dimensionaron en estacones de $10 \mathrm{~cm}$ x $10 \mathrm{~cm}$ x $100 \mathrm{~cm}$. Para la prueba soil block, se usó la especie Ceiba pentandra, la cual se adquirió en un aserradero de Bogotá, D.C.

\section{DESCRIPCIÓN ANATÓMICA}

Para la descripción anatómica de la madera de la especie Caryodaphnopsis cogolli van der Werff, se observaron y se describieron las estructuras de la madera con una lupa de $10 \mathrm{X}$, siguiendo la metodología propuesta por el Laboratorio de Tecnología de Maderas "José Anatolio Lastra Rivera" de la Universidad Distrital (Grande \& Polanco, 2009). 
Durabilidad natural y descripción anatómica de la madera de la especie Caryodaphnopsis cogolloi van der Werff

\section{PREPARACIÓN DE PROBETAS PARA ESTABLECIMIENTO DE ENSAYO DE DURABILIDAD NATURAL}

El ensayo de durabilidad natural se basó en dos metodologías: soil block, bajo la norma NTC $1127 \mathrm{de}$ 1994, transferida por la norma americana ASTM D 2017 - 63 Método acelerado para evaluar la durabilidad natural de la madera a la pudrición, y agar block, bajo la norma UNE EN 350-1 de 1995 Durabilidad de la madera y de los materiales derivados de la madera: Durabilidad natural de la madera maciza: Parte 1: Guía para los principios de ensayo y clasificación de la durabilidad natural de la madera.

Las probetas se dividieron en dos grupos. Las primeras se obtuvieron del dimensionamiento de las piezas traídas de campo. Las piezas de madera fueron seccionadas a $2.5 \mathrm{~cm}$ x $2.5 \mathrm{~cm} \times 1.0 \mathrm{~cm}$, con la menor dimensión en sentido paralelo al grano, luego se dejaron secar al aire libre con el fin de alcanzar al contenido de humedad de equilibrio.

El segundo grupo correspondió a las probetas o los bloques de alimentación, necesarios para el desarrollo inicial del hongo una vez realizado el montaje de soil block. La madera utilizada para la obtención de estas probetas fue de la especie ceiba bonga (Ceiba pentandra), cuya durabilidad natural conocida es baja. Se seleccionaron listones de $3.4 \mathrm{~cm} \times 4.0 \mathrm{~cm} \times 100 \mathrm{~cm}$ en probetas de $0.5 \mathrm{~cm}$ x $3.0 \mathrm{~cm}$ x $4.0 \mathrm{~cm}$, con la mayor dimensión en dirección paralela al grano.

\section{CULTIVO DE HONGOS}

Para el desarrollo de esta investigación se utilizaron dos especies de hongos xilófagos. El primero de pudrición blanca, Trametes versicolor Pilát, y el segundo de pudrición marrón, Gloeophyllum trabeum Murr. Las cepas fueron proporcionadas por la sección de Protección de la Madera del Laboratorio Nacional de Productos Forestales de la Universidad de Los Andes (Mérida, Venezuela).
Como medio de cultivo para la réplica de los dos hongos de interés se empleó Agar extracto de malta. Su preparación consistió en agregar a un vaso de precipitado $31.28 \mathrm{~g}$ de agar extracto de malta y $969 \mathrm{ml}$ de agua destilada, llegando así a 1 lt de solución, la cual se colocó en un plato caliente con agitador a $300^{\circ} \mathrm{C}$, durante $20 \mathrm{~min}$ aproximadamente. Una vez transcurrido este tiempo, la mezcla obtenida se vertió en un erlenmeyer de $500 \mathrm{ml}$, luego se selló con gasa y papel aluminio, con el objeto de evitar el contacto con el ambiente y posibles derrames al momento de realizar el proceso de autoclavado. Después, la solución preparada se introdujo en autoclave durante 90 minutos, a una presión de 15 psi y $121^{\circ} \mathrm{C}$. Finalizado este proceso, el medio se extrajo de la autoclave y se dejó enfriar un poco. Por último, en el interior de la cámara de flujo laminar se llenaron en promedio unas 40 cajas petri, previamente esterilizadas en estufa a una temperatura de $105^{\circ} \mathrm{C}$, durante 4 horas, con $20 \mathrm{ml}$ de medio cada una, y se dejaron allí aproximadamente 24 horas antes de realizar la inoculación de los hongos.

Para la inoculación de los hongos se extrajeron con ayuda de una pipeta pasteur, cinco muestras de las cepas originales, tanto de G. trabeum Murr como de T. versicolor Pilát. Cada inóculo se colocó en el interior de las cajas petri preparadas previamente. Una vez inoculadas, estas se sellaron con parafilm y se marcaron con fecha de inoculación y tipo de hongo. Posteriormente se llevaron al cuarto de incubación durante un periodo aproximado de dos semanas para que cubrieran la totalidad del medio de cultivo.

\section{PREPARACIÓN DE SUSTRATO SUELO}

Se tomó tierra negra, se pasó por un tamiz $\mathrm{N}^{\mathrm{o}} 6$, y se calculó la retención de agua hasta que se encontrara en un $40 \%$ aproximadamente, lo cual se logró midiendo una cantidad de agua diferente en 7 frascos hasta que el nivel de escurrimiento del suelo fuera mínimo (NTC 1127, 1994). Luego se depositaron en los frascos cantidades de suelo hasta un $50 \%$ de su capacidad, correspondiente a $166 \mathrm{~g}$, la cual se distribuyó de manera uniforme con el fin de facilitar el posterior montaje. Los frascos se llevaron a autoclave, teniendo en cuenta que la tapa 
no estuviera ajustada, hasta alcanzar una presión de 15 psi y una temperatura de $121^{\circ} \mathrm{C}$, durante un tiempo entre 90 y $120 \mathrm{~min}$. Finalizado este proceso, los frascos se extrajeron y fueron llevados a la cámara de flujo laminar con el fin de evitar su contaminación antes del montaje.

\section{PREPARACIÓN DE SUSTRATO AGAR}

Para preparar este sustrato se siguió el mismo procedimiento utilizado en la preparación del medio de cultivo para las réplicas de los hongos de pudrición. Una vez el agar cumplió los 15 min en plato caliente a $300^{\circ} \mathrm{C}$, se vertieron $100 \mathrm{ml}$ de agar en los frascos de ensayo, se le colocaron las tapas sin cerrarlos herméticamente, luego se colocaron en autoclave durante un tiempo aproximado de 90 minutos, y finalmente los frascos fueron llevados a la cámara de flujo laminar, con el fin de evitar su contaminación (UNE EN 350-1, 1995).

\section{MONTAJE DEL ENSAYO}

Para soil block: en el interior de la cámara de flujo laminar se tomaron las probetas de alimentación previamente esterilizadas en autoclave durante 90 minutos y se introdujeron en cada uno de los frascos de ensayo con un inóculo de cada hongo. Luego se cerraron y fueron llevadas al cuarto de incubación durante tres semanas aproximadamente.

Para agar block: los frascos se inocularon en la cámara de flujo laminar con cada uno de los hongos objeto de estudio, se cerraron y fueron llevados al cuarto de incubación durante un periodo aproximado de tres semanas.

Una vez que los bloques de alimentación y la totalidad del agar fueron cubiertos por los hongos, se introdujeron dos probetas de la especie objeto de estudio por frasco, dejando la sección transversal en contacto con los bloques de alimentación para soil block (figura 1a). En el caso del agar block, se introdujeron rejillas previamente esterilizadas y sobre estas se colocaron las probetas de estudio, con la sección transversal en contacto con el hongo (figura 1 b). Cabe resaltar que las probetas objeto de estudio se secaron previamente a $61{ }^{\circ} \mathrm{C}$ por 24 horas y luego fueron pesadas, para controlar la pérdida de peso al finalizar cada periodo de exposición.

Una vez realizado el montaje, los frascos debidamente rotulados con la inicial del tratamiento, para este caso hongo ( $\mathrm{T}$ o $\mathrm{G}$ ) y sustrato ( $\mathrm{S}$ o A), se llevaron de nuevo al cuarto de incubación a $25^{\circ} \mathrm{C}$ y $70 \%$ de humedad relativa.

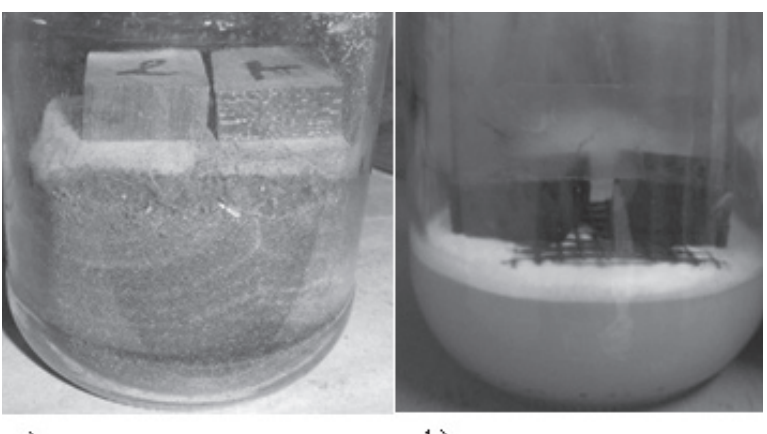

a)

b)

Figura 1. Montaje del ensayo a) Soil block b) Agar block

\section{PERIODO DE EXPOSICIÓN}

El periodo de exposición de las probetas fue de 16 semanas, según lo establecido en las normas NTC 1127 y UNE EN 350-1.

Cada cuatro semanas se seleccionaron dos frascos de forma aleatoria, de los cuales se extrajeron las probetas y se les retiró el micelio cuidadosamente. Luego tres de estas fueron pesadas a las mismas condiciones en las que se tomó el peso antes de realizar el montaje y una fue llevada a nevera, con la cual se realizó el posterior análisis microscópico del ataque.

\section{ÍNDICES DE DURABILIDAD}

Una vez culminado el periodo de exposición de 16 semanas, la madera se clasificó según los rangos de resistencia a la pudrición otorgados por las normas NTC 1127 y UNE EN 350-1 (tablas 1 y 2). 
Durabilidad natural y descripción anatómica de la madera de la especie Caryodaphnopsis cogolloi van der Werff

Tabla 1. Clasificación de durabilidad natural según la norma NTC 1127

\begin{tabular}{ccc}
\hline Perdida promedio de masa (\%) & Masa residual promedio (\%) & $\begin{array}{c}\text { Grado de resistencia al hongo xilófago } \\
\text { (durabilidad natural) }\end{array}$ \\
\hline $\mathbf{0}-\mathbf{1 0}$ & $90-100$ & Altamente resistente \\
$\mathbf{1 1}-\mathbf{2 4}$ & $76-89$ & Resistente \\
$\mathbf{2 5}-\mathbf{4 4}$ & $56-75$ & Moderadamente resistente \\
$\mathbf{4 5}$ en adelante & 55 o menos & Poco resistente \\
\hline
\end{tabular}

Fuente: NTC 1127 (1994).

Tabla 2. Clasificación de durabilidad natural según la norma UNE EN 350-1

\begin{tabular}{ccc}
\hline Clases de durabilidad & Descripción & Resultados de ensayos de laboratorio (\%) \\
\hline $\mathbf{1}$ & Muy durable & Menor a 15 \\
$\mathbf{2}$ & Durable & 15 a 30 \\
$\mathbf{4}$ & Medianamente durable & 30 a 60 \\
$\mathbf{5}$ & Poco durable & 60 a 90 \\
& No durable & Mayor a 90 \\
\hline
\end{tabular}

Fuente: UNE EN 350-1 (1995).

\section{PATRONES DE DEGRADACIÓN}

Para la evaluación de las características de la pudrición generada por los dos tipos de hongo utilizados, se realizaron cortes finos de las probetas, se tiñeron con safranina al $0.1 \%$ y se observaron en microscopio óptico de luz normal Nikon Eclipse E200 MVR.

\section{RESULTADOS}

\section{DESCRIPCIÓN ANATÓMICA DE LA ESPECIE}

Madera de color castaño, sin transición abrupta entre albura y duramen. Olor fuerte y penetrante. Sabor no distintivo. Lustre alto. Grano inclinado. Textura mediana. Diseño tenue, determinado por el contraste de tejidos (figura 2). Dura y pesada.

Anillos de crecimiento distinguibles, definidos por la presencia de bandas de madera tardía sin poros (figura 3). Poros frecuentes distinguibles a simple vista, con forma ovalada.

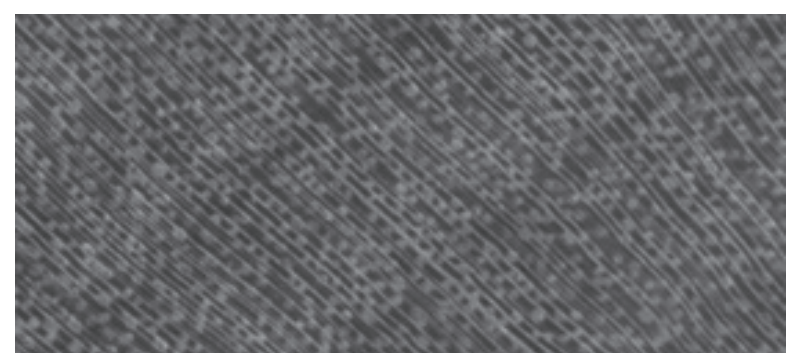

Figura 2. Diseño otorgado por contraste de tejidos

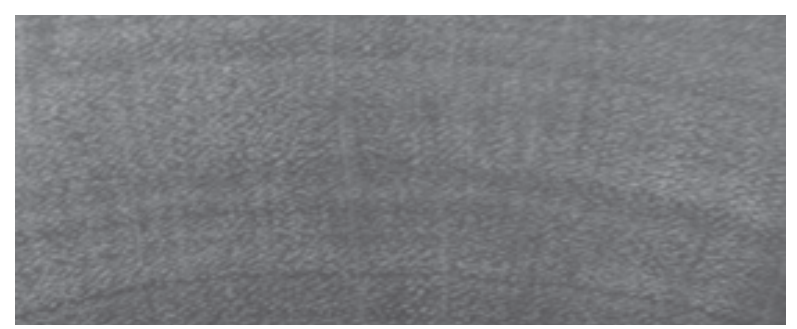

Figura 3. Anillos de crecimiento definidos por ausencia de poros en bandas de madera tardía 


\section{CRECIMIENTO DE LOS HONGOS SOBRE LAS PROBETAS DE ENSAYO}

El crecimiento de los hongos de pudrición, tanto en las probetas de agar block como en las de soil block, no tuvo un comportamiento uniforme en ninguno de los periodos de exposición; sin embargo, el crecimiento fue mayor para el hongo de pudrición blanca con respecto al de pudrición marrón (figuras 4 y 5).

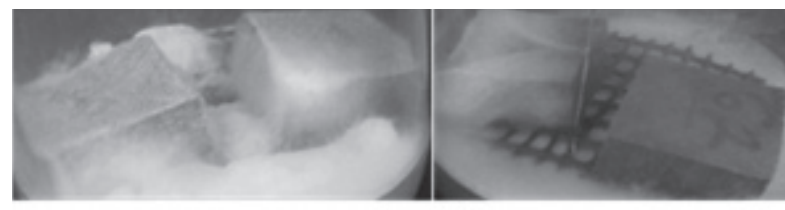

a)

b)

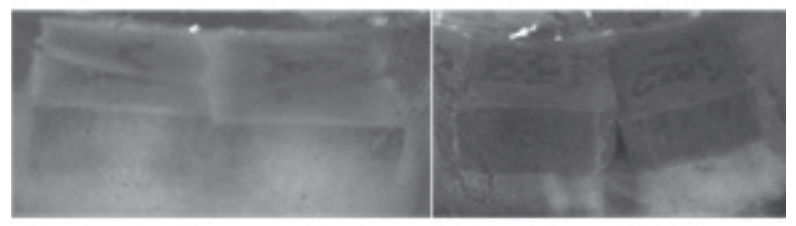

c)

Figura 4. Cubrimiento del micelio en probetas de C. $\mathrm{CO}$ golloi. $3^{\circ}$ mes de exposición a) T.versicolor-Agar block b) G.trabeum-Agar block c) T.versicolor-Soil block d) G.trabeum-Soil block.

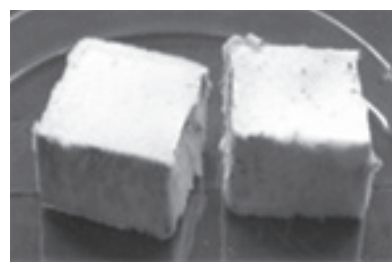

a)

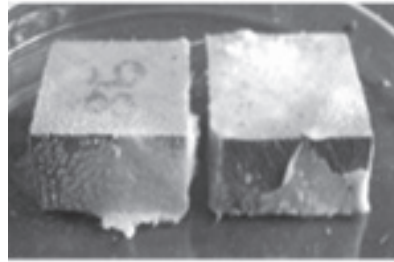

c)

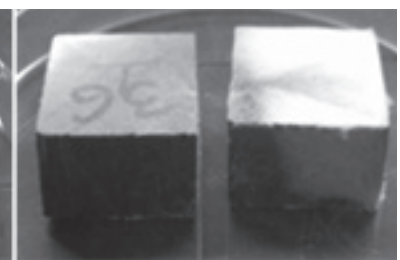

b)

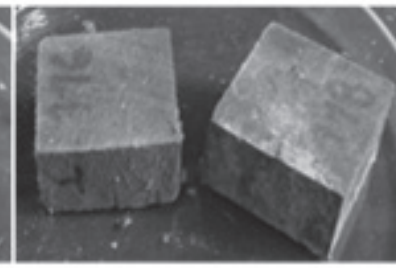

d)
Figura 5. Cubrimiento del micelio en probetas de C. $\mathrm{CO}$ golloi. $4^{\mathbf{0}}$ mes de exposición a) T.versicolor-Agar block b) G.trabeum-Agar block c) T.versicolor-Soil block d) G.trabeum-Soil block.

\section{PÉRDIDA DE PESO}

Las pérdidas de peso promedio en soil block se encontraron entre 4.6 y $7.0 \%$ para $T$. versicolor, sien- do el pico más bajo en el primer mes y el más alto en el cuarto. Para G. trabeum el rango de pérdida se encontró entre 4.5 y $8.3 \%$, alcanzando el valor más bajo en el primer periodo de exposición y el más alto en el último (figura 6).

\section{PERDIDA DE PESO PROMEDIO SOIL BLOCK}

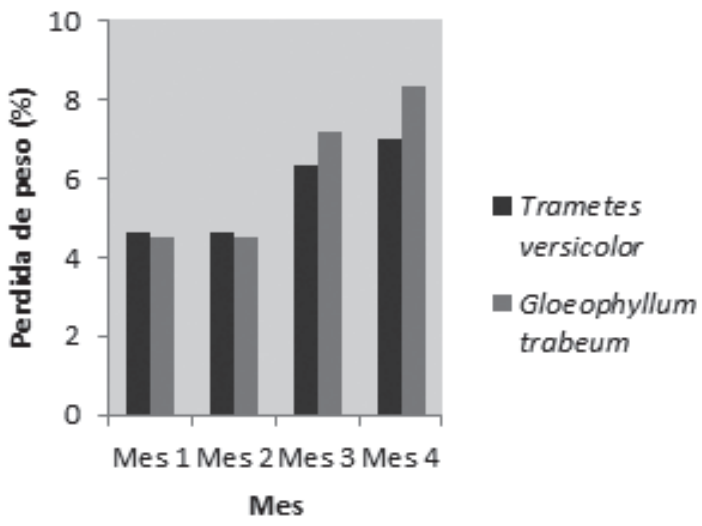

Figura 6. Pérdida porcentual de peso promedio mensual soil block

En agar block las pérdidas de peso promedio para el hongo de pudrición blanca, T. versicolor, fluctuaron entre 4.5 y $7.3 \%$, con el menor porcentaje en el primer mes y el mayor en el cuarto, mientras que para el hongo de pudrición marrón, G. trabeum, los valores se encontraron entre 4.8 y $7.6 \%$, siendo el más bajo para el primer periodo de exposición y el más alto para el ultimo (figura 7).

\section{PERDIDA DE PESO PROMEDIO AGAR BLOCK}

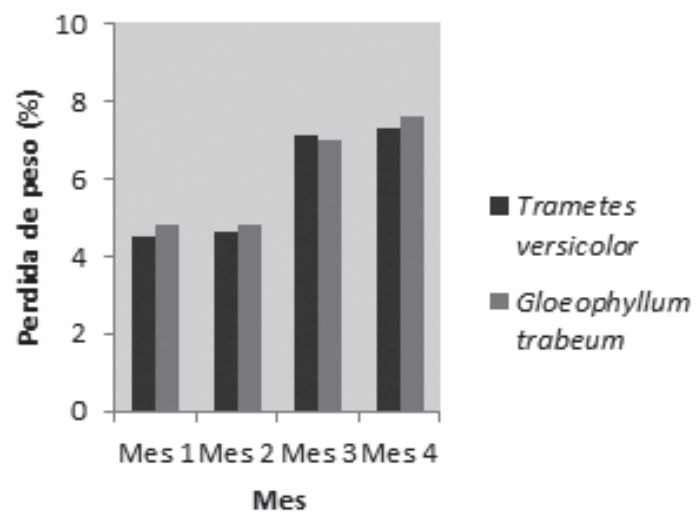

Figura 7. Pérdida porcentual de peso promedio mensual agar block 
Dado que las pérdidas de peso promedio durante todos los periodos de exposición tanto en soil block como en agar block oscilaron entre 4.5 y $8.5 \%$, la madera de $C$. cogolloi se clasifica como altamente resistente según las normas NTC 1127 (tabla 1) y EN 350-1 (tabla 2).

\section{PATRONES DE DEGRADACIÓN}

El patrón de ataque observado en las probetas permitió determinar las formas como los dos hongos de pudrición se establecieron dentro de la madera de $C$. cogolloi, su desarrollo dentro de las diferentes estructuras anatómicas, así como el tipo de ataque que generaron en la pared celular. Cabe resaltar que entre el método agar block y el soil block no se presentó diferencia alguna en cuanto a patrones de degradación se refiere.

El hongo $T$. versicolor colonizó la madera de $C$. cogolloi vía vasos y parénquima radial. En los dos primeros meses no se apreció degradación de ninguna de las estructuras anatómicas de la madera (figuras 8a y 9a). Después de finalizar el segundo mes de incubación, hifas muy delgadas con fíbulas comenzaron a desarrollarse dentro de los radios (figura 10b). En la evaluación microscópica del mes

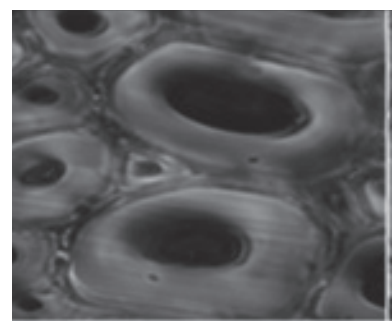

a)

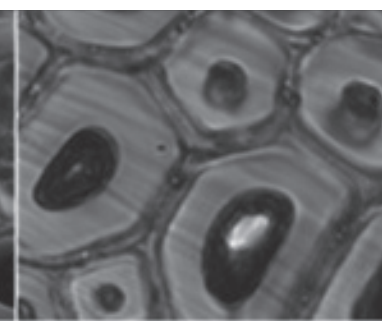

b)
Figura 8. Muestras $1^{\circ}$ mes a) T.versicolor-Soil block b) G.trabeum-Soil block. Aumento 100x tres los radios fueron más susceptibles a la degradación, mientras que los vasos presentaron mayor resistencia al deterioro. Se pudo apreciar una leve erosión de la pared celular desde el lumen hacia la lámina media en algunas células (figura 10a). Para el cuarto mes se observó que el paso de las hifas se realizó de manera pasiva a través de las punteaduras, generándose el ensanchamiento de estas (figura 11a). Además, en el plano tangencial se evidenció la erosión de los radios (figura 12a). Nunca se observaron agujeros de penetración, los cuales se deben a una penetración activa. Estos patrones de crecimiento no produjeron cambios significativos en la degradación de los diferentes tejidos de la madera.

El hongo G. trabeum colonizó la superficie longitudinal de la madera de $C$. cogolloi a través de los radios, pasando al sistema celular axial y elementos vasculares después del tercer mes. Hasta este momento pocas hifas lograron establecerse en los diferentes tejidos de la madera, por lo que no se presentaron síntomas de erosión (figuras 8b, 9b y 10c). Las observaciones del cuarto mes demostraron que algunas células dentro de la madera fueron severamente degradadas, pero este comportamiento no se generalizó en todas las células. No se observaron grietas dentro de las paredes y se mantuvo la rigidez de la estructura y su forma original (figuras 11b y 12b).

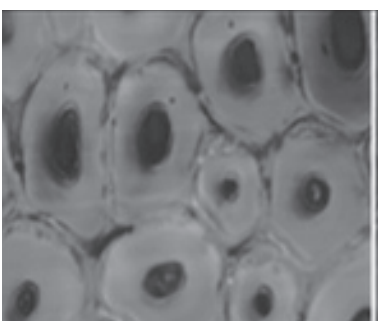

a)

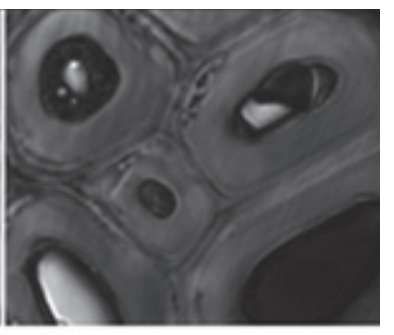

b)
Figura 9. Muestras $2^{\circ}$ mes a) T.versicolor-Soil block b) G.trabeum-Agar block. Aumento 100x

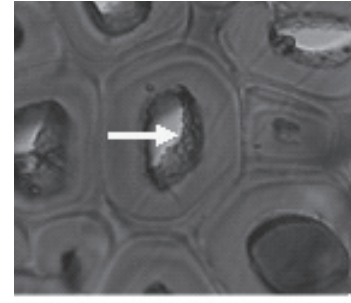

a)

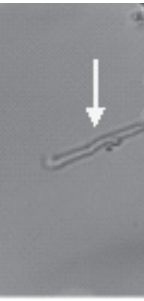

b)

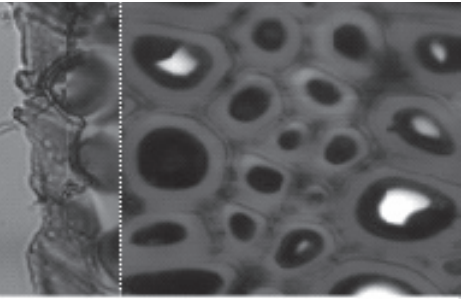

c)

Figura 10. Muestras $3^{\circ}$ mes a) T.versicolor-Agar block. Erosión de la pared celular. Aumento 100x b) T.versicolorAgar block. Hifa con fíbula en plano radial. Aumento 100x c) G.trabeum-Soil block. Aumento 40x 


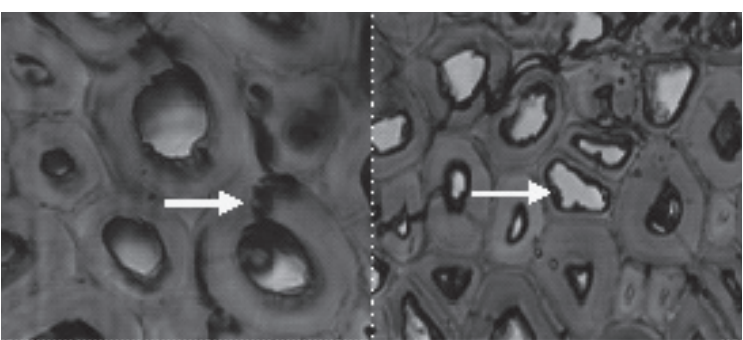

a)

h)

Figura 11. Muestras $4^{\circ}$ mes a) T.versicolor-Agar block. Ensanchamiento de punteaduras. Aumento 100x b) G.trabeum-Agar block. Degradación de la pared celular. Aumento 40x

\section{ANÁLISIS}

\section{DESCRIPCIÓN ANATÓMICA DE LA ESPECIE}

La importancia de realizar la descripción radica en el conocimiento que se ofrece de una especie cuya anatomía de la madera no se encuentra registrada y de la cual la información es bastante limitada, por lo cual su manejo y uso no se encuentra controlado. Si bien se encuentra reportada entre las especies en peligro de extinción por su distribución en pequeñas extensiones del país, no se evita el uso de la especie por parte de las comunidades locales, por lo cual el presente estudio permite que se conozcan las características de la especie Caryodaphnopsis cogolloi van der Werff, con miras a un mejor uso de esta, incentivando también la búsqueda de especies con características similares que puedan ser utilizadas como sustitutas, disminuyendo así la presión sobre ella.

En la búsqueda de especies del mismo género, que en un momento dado pudiesen sustituir al C. cogolloi en cuanto a propiedades de la madera se refiere, la literatura solo reporta la descripción anatómica para la especie Caryodaphnopsis fosteri van der Werff, por lo cual para efectos comparativos esta será la única especie de este género que se tendrá en cuenta en esta investigación.

Gonzales (2011) describe las características anatómicas de la especie Caryodaphnopsis fosteri van der Werff (Palo caramelo). Reporta como resultado que la madera de las dos especies no posee transi-

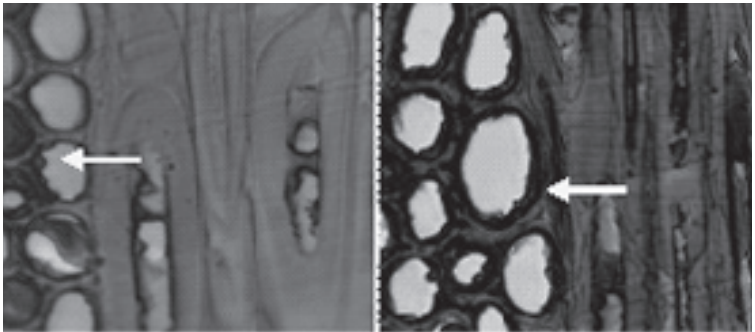

a)

b)

Figura 12. Muestras $4^{\circ}$ mes. Erosión del parénquima radial en plano tangencial a) T.versicolor-Agar block b) G.trabeum-Soil block. Aumento 40x

ción entre albura y duramen: el lustre en C. cogolloi es alto mientras que en $C$. fosteri está ausente. En cuanto al grano, en la especie objeto de estudio es inclinado, difiriendo de C. fosteri que presenta grano entrecruzado. Por otro lado, el veteado en C. cogolloi es tenue, determinado por contraste de tejidos, mientras que en $C$. fosteri no se distingue veteado alguno. Otras características como sabor ausente, olor distintivo y textura media concuerdan en las dos especies.

En cuanto a poros, en las dos especies son visibles a simple vista, frecuentes, solitarios y en menor proporción en múltiplos radiales, con porosidad difusa. Los anillos de crecimiento se diferencian fácilmente en las dos especies y las dos poseen parénquima paratraqueal.

\section{CRECIMIENTO DE LOS HONGOS SOBRE LAS PROBETAS DE ENSAYO}

En cuanto al crecimiento de los hongos sobre las probetas de C. cogolloi, visualmente no se pudo definir un patrón uniforme; contrariamente a lo registrado por González (1970), donde en especies como Couma macrocarpa (Leche caspi), Tabebuia pentaphyla (Tuhuari) y Pousoqueria longifolia (Raya caspi), el hongo de pudrición blanca cubrió las probetas de manera uniforme y abundante en sustrato agar. Mora (1998) reportó el crecimiento del $T$. versicolor y $G$. trabeum sobre madera de Pinus caribaea (Pino caribe), Pterocarpus acapulcensis (Drago) y Tabebuia serratifolia (Cura- 
rire), teniendo para el primer hongo un desarrollo abundante sobre la madera de $P$. acapulcensis, leve sobre $P$. caribaea y nulo sobre $T$. serratifolia, al finalizar los cuatro periodos de exposición. Para $G$. trabeum encontró un crecimiento vigoroso sobre $P$. caribaea, y muy escaso sobre $T$. serratifolia y $P$. acapulcensis al terminar el ensayo. Si bien en C. cogolloi no se presentó uniformidad en el crecimiento, se encuentra similitud con la madera de Drago, en la que el crecimiento del $T$. versicolor fue más evidente que el de G. trabeum.

\section{PÉRDIDA DE PESO}

De acuerdo con los resultados obtenidos tanto en soil block como en agar block, las pérdidas de peso promedio de las probetas a lo largo del ensayo no superaron el $10 \%$ para el primer método y el $15 \%$ para el segundo, por lo que la madera de C. $\mathrm{Co}$ golloi se ubicó en la clasificación más alta de resistencia establecida por las normas NTC 1127 y EN 350-1, considerándose como una madera con un gran potencial de uso en intemperie, en contacto directo con el suelo, donde el riesgo de pudrición es bastante alto (García, 1974), así como en interiores, donde el riesgo se reduce. Se comprueba así la evidencia empírica otorgada por las comunidades locales de Magdalena Medio colombiano.

Al realizar un análisis comparativo con otros autores, no se encontraron estudios de durabilidad natural para la especie C. cogolloi (Yumbé), por lo cual se recurrió a comparar los resultados obtenidos con investigaciones similares de otras especies.

González (1970) determinó la durabilidad natural de 53 especies forestales del Perú, entre las cuales especies como Perebea chimicua (Chimicua blanca), Sterculia tessmannii (Sapoena), Terminalia oblonga (Huarapo) y Couropita peruviana (Ayahuma) presentaron una pérdida de peso promedio de $8.45,32.43,18.45$ y $5.92 \%$, respectivamente, tras el ataque del hongo $T$. versicolor, en un periodo de exposición de tres meses, con sustrato agar. Comparando los resultados de estas especies con la especie C. cogolloi (Yumbé), en este mismo periodo y bajo la exposición al mismo hongo y sus- trato, esta presento una pérdida de peso promedio de $7.1 \%$, ubicándose en la misma clasificación de resistencia (tabla 2) de la especie Perebea chimicua y Couropita peruviana, siendo la primera un poco menos durable y la segunda un poco más que el Yumbé. Caso contrario se observa en las dos especies restantes, donde los porcentajes de pérdida de peso superan al de la especie estudiada en más de un $50 \%$, siendo esta mucho más durable frente al ataque del hongo de pudrición blanca.

Juacida \& Liese (1980) realizaron un estudio similar al de González, utilizando otras especies forestales y hongos xilófagos para su estudio, entre estos el segundo hongo de interés para esta investigación (G. trabeum), el periodo de exposición fue de tres meses y el sustrato agar. Las especies estudiadas fueron Nothofagus dombeyi (Coigüe), Laurelia philippiana (Tepa), Eucryphia cordifolia (Ulmo) y Aextoxicon punctatum (Olivillo), las cuales registraron al finalizar el periodo de exposición pérdidas de peso de $5.7 \%$ para el Coigüe, $52.5 \%$ para la Tepa, $21.6 \%$ para el Ulmo y $2.9 \%$ para el Olivillo. En relación con la pérdida promedio de masa del Yumbé, que para el mismo hongo y periodo de exposición fue de $7.0 \%$, esta especie es más durable que especies como el Coigüe y Tepa, pero considerablemente menos resistente al ataque de hongos de pudrición marrón que el Ulmo y el Olivillo.

Por otro lado, Mora (1998) investigó las especies Pterocarpus acapulsensis (Drago) y Tabebuia serratifolia (Curarire), utilizando como sustrato suelo y como hongos de pudrición los mismos utilizados en el desarrollo de este estudio, durante un periodo de exposición de cuatro meses, teniendo al final que la primera especie perdió un $53.32 \%$ de su peso inicial tras el ataque del hongo de pudrición blanca y aproximadamente un $20 \%$ por causa del hongo de pudrición marrón, mientras que la segunda especie no superó el $2 \%$ de perdida promedio para los dos hongos. La especie C. cogolloi tuvo una pérdida de $7.0 \%$ para el primer hongo y $8.3 \%$ para el segundo al finalizar los cuatro meses de ensayo en soil block, por lo que se ubica en una categoría de resistencia (Tabla 1a) igual a la 
especie T. serratifolia, pero en una mayor que $P$. acapulsensis, teniendo así en promedio una vida útil menor a la de la primera especie, que si bien se encuentra en la misma categoría, el porcentaje de pérdida de peso de esta fue de menos de la mitad que el observado en el Yumbé, pero una vida útil mucho mayor que la segunda especie, llegando a tener hasta 10 años más en servicio (Junac, 1988) en su estado natural.

Cardenas \& Polanco (2004) utilizaron los mismos hongos y sustratos usados por Mora y por los presentes autores, con la diferencia de que estos usaron cepas proporcionadas por el United States Department of Agriculture -USDA-, investigaron la durabilidad natural de la especie Trichospermun colombianum (Algodoncillo), obteniendo que esta tenía una mejor respuesta al hongo de pudrición parda, con un $14.9 \%$ de pérdida de peso al finalizar los cuatro meses de exposición, que al hongo de pudrición blanca, con un $33.34 \%$ de pérdida. Si se compara con los resultados de esta investigación, se puede decir que la madera de T. colombianum es menos resistente en su estado natural al ataque de los dos hongos de pudrición que la madera de $C$. cogolloi, con una diferencia de pérdida de peso de $26.34 \%$ para $T$. versicolor y $7.9 \%$ para G. trabeum.
En 2006, Holmquist et al. determinaron la durabilidad natural de las especies Campsiandra comosa (Chigo) y Caraipa llanorum (Saladillo) y obtuvieron como resultado que la especie Chigo transcurridos los cuatro meses de exposición en sustrato agar perdió en promedio un $2.5 \%$ para $T$. versicolor, mientras que el Saladillo perdió un $6.93 \%$ para el mismo hongo. Para G. trabeum el Chigo tuvo una pérdida mayor que el Saladillo, con 3.88 y $2.95 \%$ respectivamente. En comparación, el Yumbé presentó una durabilidad natural menor a la del Chigo y el Saladillo, con una diferencia de $4.8 \%$ con respecto a la primera especie y $0.37 \%$ con respecto a la segunda, después del ataque del hongo T. versicolor y de 3.72 y $4.65 \%$ por causa del G. trabeum, siendo la resistencia al hongo de pudrición blanca muy similar a la ofrecida por la especia C. llanorum.

Al comparar gráficamente la durabilidad natural, se tiene que la especie Caryodaphnopsis cogolloi, en comparación con las latifoliadas estudiadas por los autores antes descritos, tiene un muy buen comportamiento tanto al ataque del hogo de pudrición blanca (figura 13) como al del hongo de pudrición marrón (figura 14), ubicándose entre las especies con pérdidas de peso promedio más bajas.

DURABILIDAD NATURAL DE DIFERENTES ESPECIES LATIFOLIADAS BAJO EL ATAQUE DE Trametes versicolor

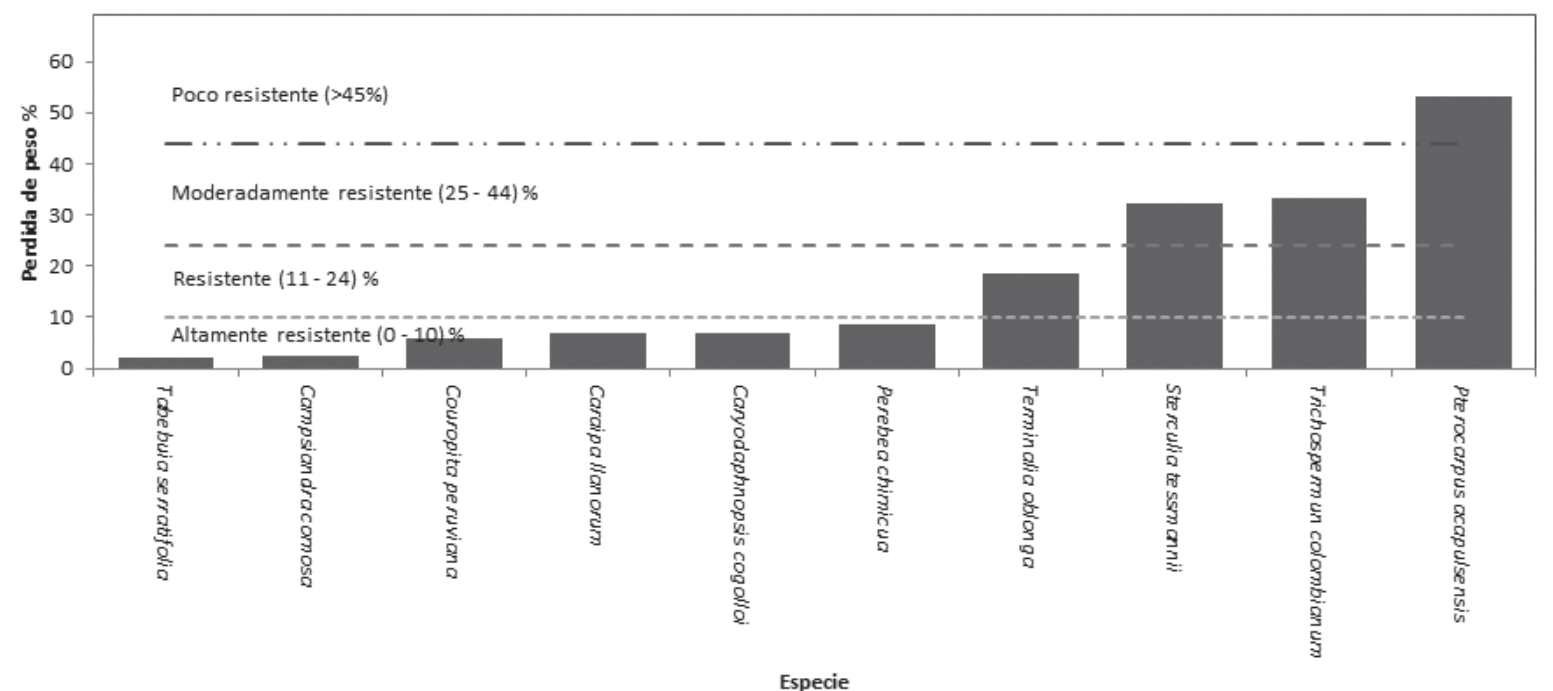

Figura 13. Durabilidad natural de diferentes especies latifoliadas frente al ataque de Trametes versicolor 


\section{DURABILIDAD NATURAL DE DIFERENTES ESPECIES LATIFOLIADAS BAJO EL ATAQUE DE Gloeophyllum trabeum}

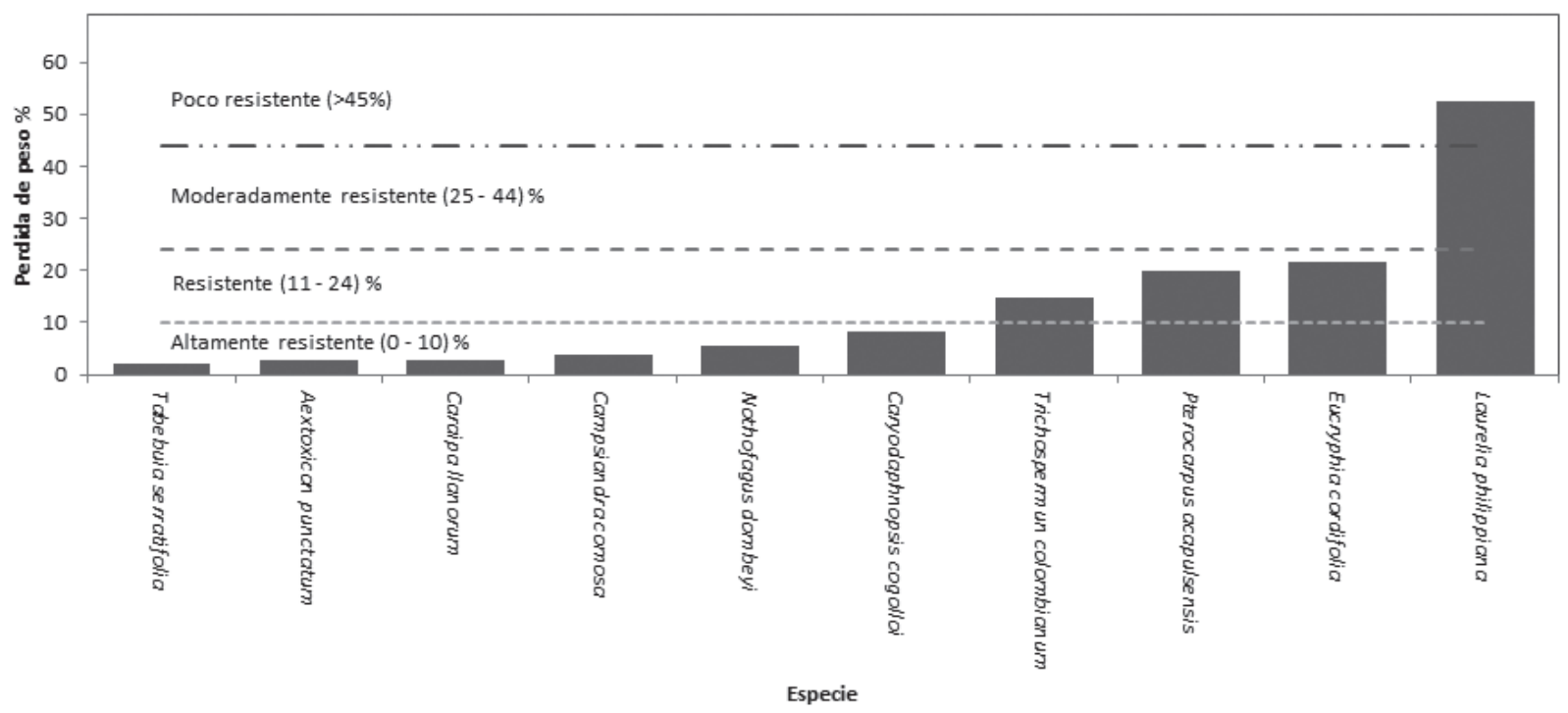

Figura 14. Durabilidad natural de diferentes especies latifoliadas al ataque de Gloeophyllum trabeum

Si bien esta respuesta a la pudrición hace del Yumbé una especie de interés y con alto potencial comercial, debe tenerse en cuenta que es una especie forestal catalogada en peligro de extinción crítico, dado su distribución en superficies reducidas y la sobreexplotación por comunidades locales (Cárdenas \& Salinas, 2007), por lo cual realizar este tipo de comparaciones (figuras 11 y 12) puede contribuir a la apreciación de la especie por parte de los pobladores locales, lo que estimula su manejo y buen uso y prolonga así su permanencia en el tiempo.

\section{PATRONES DE DEGRADACIÓN}

Los hongos de pudrición blanca como el $T$. versicolor colonizan fácilmente en la mayoría de los casos las maderas latifoliadas, debido al tipo de lignina presente (Eaton \& Hale, 1993). Varios estudios han demostrado que la lignina tipo siringil presente en las latifoliadas es más fácil de degradar enzimáticamente que la lignina guayacil por los hongos de pudrición blanca (Eriksson et al., 1990). En términos generales, en las maderas latifoliadas las vías de penetración inicial así como los patro- nes de crecimiento de $T$. versicolor se dan a través de los vasos, parénquima radial y axial. En el caso de la especie C. cogolloi, aun cuando escasas hifas lograron colonizar la madera, estas no produjeron erosiones a gran escala en ninguno de los tejidos, lo que demuestra la resistencia natural de esta madera contra hongos de pudrición blanca.

El colapso de la pared celular de algunas células en la madera de C. cogolloi causado por G. trabeum refleja el fuerte ataque sobre los componentes celulolíticos de la pared celular, específicamente sobre las cadenas de celulosas y hemicelulosas, por parte de este hongo (Eaton \& Hale, 1993), pero aun cuando se dio el crecimiento de $G$. trabeum sobre los bloques, este utilizó las probetas solamente como soporte para su desarrollo, debido a que internamente no fue sino hasta finalizar el periodo de incubación cuando se identificó un bajo grado de deterioro sobre la pared celular, lo que indica alta resistencia de esta madera al ataque de los hongos de pudrición marrón. Este comportamiento se presentó en la madera de la especie Tabebuia serratifolia, en la cual no fue sino hasta después de finalizar el segundo mes de 
incubación cuando escasas hifas lograron penetrar vías, vasos y radios sin causar ningún tipo de erosión sobre las células (Encinas \& Mora, 2003).

\section{CONCLUSIONES}

Como no existe información alguna publicada acerca de la anatomía macroscópica de la madera de la especie Caryodaphnopsis cogolloi van der Werff, el presente reporte puede considerarse el primero al respecto.

La especie Caryodaphnopsis fosteri presenta características anatómicas desde el punto de vista macroscópico muy similares al C. cogolloi; sin embargo, existen diferencias que le otorgan particularidades únicas a cada especie.

La madera de C. cogolloi en su estado natural se clasificó como altamente resistente al ataque del hongo de pudrición blanca $T$. vesicolor $\mathrm{y}$ al de pudrición marrón G. trabeum, al tener una pérdida de peso promedio menor al $10 \%$ al finalizar el ensayo, siendo suficientes las 16 semanas de exposición para determinar el índice de durabilidad natural, dado que las diferencias de pérdida de peso entre los últimos dos periodos de incubación no superaron el 1\%.

Este índice de durabilidad natural genera un alto interés comercial sobre la especie, pero dada su distribución restringida a pequeñas zonas del Magdalena Medio colombiano y el aprovechamiento intensivo a nivel local, se hace susceptible a la extinción, por lo cual esta investigación contribuye a su conocimiento, estimulando su manejo y buen uso y prolongando su permanencia en el tiempo.

\section{AGRADECIMIENTOS}

A los campesinos del Magdalena Medio colombiano quienes suministraron la madera y sus apreciaciones sobre esta.

Al señor Jorge Mayorga, carpintero de la Universidad Distrital Francisco José de Caldas, por procesar la madera necesaria para la investigación.
Al Laboratorio Nacional de Productos Forestales de Mérida Venezuela, que prestó sus instalaciones y proporcionó las cepas necesarias para el desarrollo de esta investigación.

\section{REFERENCIAS BIBLIOGRÁFICAS}

Akhtar, M., Blanchette, R., \& Kent, T. (1998). Fungal delignification and biomechanical pulping of wood. Advances in Biochemical Engineering Biotechnology, 57, 159-195.

American Society for Testing and Materials -ASTM- (1986). Anual book of standart (Designación D: 2017-63). Standard Method of Accelerated Laboratory Test of Natural Decay Resistance of Woods.

Bobadilla, E. A., Pereyra, O., Silva, F., \& Stehr, A.M. (2005). Durabilidad natural de la madera de dos especies aptas para la industria de la construcción. Floresta, Curitiba, PR, 35 (3), 419-428.

Breen, A., \& Singleton, F.L. (1999). Fungi in lignocellulose breakdown and biopulping. Current Opinion in Biotechnology, 10, 252-258.

Cárdenas, L.D., \& Salinas, N.R. (eds.). (2007). Libro rojo de plantas de Colombia. Volumen 4. Especies maderables amenazadas. Primera parte. Serie libros rojos de especies amenazadas de Colombia. Bogotá D.C: Instituto Amazónico de Investigaciones Científicas -Sinchi-, Ministerio de Ambiente, Vivienda y Desarrollo Territorial. $232 \mathrm{p}$.

Cardenas, D., \& Polanco, C. (2004). Durabilidad natural de la madera de Trichospermun colombianum (algodoncillo). Revista Colombia Forestal, 8, 120-129.

Córdoba, K.A. (2009). Resistencia natural de Guadua angustifolia Kunth. al ataque de hongos ligninolíticos como alternativa hacia nuevas posibilidades de uso (Tesis de maestría). Bogotá D. C: Pontificia Universidad Javeriana. 90 p. 
Durabilidad natural y descripción anatómica de la madera de la especie Caryodaphnopsis cogolloi van der Werff

Eaton, R., \& Hale, M. (1993). Wood: Decay, pests and protection. Londres: Chapman and Hall. 546 p.

Encinas, O., \& Mora, N. (2003). Patrones de degradación de las maderas de Pino caribe, Curarire y Drago por Gloeophyllum trabeum, Trametes versicolor y Pycnoporus sanguineus. Revista Forestal Venezolana, 47 (1), 1-14.

Equipo Subregión de Vélez (1998). Programa de Desarrollo y Paz del Magdalena Medio - Corregimiento de La India. Informe general del proceso. Landázuri, Santander. Colombia. 7 p.

Eriksson, K., Blanchette, R., \& Ander, P. (1990). Microbial and enzymatic degradation of wood and wood components. Berlín: Springer-Verlag. 407 p.

Findlay, W.K. (1985). The nature and durability of wood. En W. K. Findlay (ed.). Preservation timber in the tropics (pp. 1-13). Martinus Nijhoff/Dr W. Junk Publishers. The Netherlands.

García Sola, E. (1974). Diseño y tecnología para viviendas de interés social. Facultad de Ingeniería de la Universidad Nacional del Nordeste. Departamento de Física, Química y Geociencia. Argentina.

González, F. (1970). Durabilidad natural de 53 especies forestales de Yurimaguas. Revista Forestal del Perú, 4, 1-25.

Gonzales, I. (2011). Atlas de maderas selva central. Perú. 168 p.

Grande, C. \& Polanco, C. (2009). Descripción anatómica de la madera de 40 especies del bosque altoandino en Guasca, Cundinamarca. Colombia Forestal, 10 (20), 180 - 206.

Guevara, L., \& Lluncor, D. (1993). Durabilidad natural y adquirida de 27 maderas tropicales en condición de campo. Folia Amazonica, 5 (1-2), 203-215.
Holmquist, O., Cadenas, A., Pietrantonio, P., Piña, A., Maggiorani, A., \& Bracamonte, L. (2007). Estudio de la durabilidad natural de maderas comunes en el Bajo Apure de Venezuela II: Congrio (Swartzia serícea) y Salado (Vochysia lehmanii). Revista Forestal Latinoamericana, 41, 75-92.

Holmquist, O., Cadenas, A., Pietrantonio, P., Bracamonte, L., Colmenter, C., \& Valladares, Y. (2006). Durabilidad natural de maderas comunes en el Bajo Apure de Venezuela I: Chigo y Saladillo. Revista Forestal Latinoamericana, 39, 1-16.

Intini, M., \& Tello, M.L. (2003). Investigations on the xylophagous fungi of urban trees in Europe: Inonotusrickii (Pat.). Reidfound in Spain. Boletín de Sanidad Vegetal y Plagas, 29, 277-279.

Juacida, R., \& Liese, W. (1980). Durabilidad natural de maderas frente al ataque de hongos. Revista Bosque, 3 (2), 77-85.

Junta del Acuerdo de Cartagena -Junac- (1988). Manual del Grupo Andino para la Preservación de Maderas. Lima. 402 p.

Martínez, J. (1952). Conservación de madera en sus aspectos teóricos, industrial y económico. Madrid: Ministerio de Agricultura, Instituto Forestal de Investigación y Experiencias. 550 p.

Mohali, S., \& Castro, F. (2005). Evaluación de laboratorio de la durabilidad natural e inducida de las maderas de Pino Caribe (Pinus caribaea Mor. Var. hondurensis) y Melina (Gmelina arbórea Roxb.). Revista Copérnico, 2, 52-59.

Mora, N. (1998). Efectos del ataque de hongos de pudrición marrón y blanca sobre la durabilidad natural e inducida de tres maderas venezolanas (Tesis de Maestría). Mérida: Universidad de Los Andes, Facultad de Ciencias Forestales y Ambientales. 84 p. 
Mora, N., \& Encinas, O. (2001). Evaluación de la durabilidad natural e inducida de Pterocarpus acapulcensis, Tabebuia serratifolia y Pinus caribaea, en condiciones de laboratorio. Revista Forestal Venezolana, 45 (1), 23-31.

Norma Técnica Colombiana -NTC- 1127 (1994). Determinación de la durabilidad natural ensayo acelerado. Bogotá. 10 p.

Nunes, L.M.R., \& De Sousa, P.P. (1995). Durability, preservative treatment. En Timber Engineering Step 1 (pp. 1-8). Centrum Hout. The Netherland.

Ramírez, E., Castro, F. \& Velásquez, J. (2005). Durabilidad natural de la madera de Baraman (Catostemma commune Sandwith). Revista Copérnico, 3, 269-272.

Reforestadora Bosques del Futuro (1996). Solicitud de autorización de aprovechamiento forestal persistente clase C. Fincas Las Brisas y Aguas Frías. Inventario forestal 4\%-5\%. Bogotá D.C.
Scheffer, T.C., \& Cowling, E.B. (1966). Natural resistance of wood to microbial deterioration. Annual Review of Phytopathology, 4, 147$170 \mathrm{p}$.

UNE EN 350-1 (1995). Durabilidad de la madera y de los materiales derivados de la madera. Durabilidad natural de la madera maciza. Parte 1: Guía para los principios de ensayo y clasificación de la durabilidad natural de la madera. Madrid: Asociación Española de Normalización y Certificación.

Werff, H. van der (1988). Eight new species and one new combination of neotropical Lauraceae. Annals of the Missouri Botanical Garden, $75,402-419$.

Zabel, R. A., \& Morrell, J. J. (1992). Wood microbiology. Decay and its prevention. San Diego: Harcourt Brace Jovanovich Publishers, Academic Press. 476 p. 